Port Econ J (2014) 13:117-130

DOI 10.1007/s10258-014-0101-y

\title{
Do real interest rates converge across Latin american countries?
}

\author{
Wen Long Zhang \& Hsu-Ling Chang \& Chi-Wei Su
}

Received: 17 October 2012 / Accepted: 15 May 2014 / Published online: 5 July 2014

\# ISEG 2014

\begin{abstract}
In this study, we apply the Sequential Panel Selection Method (SPSM), proposed by Chortareas and Kapetanios (Journal of Banking and Finance 33:390-404, 2009), to investigate and assess the non-stationary properties of the real interest rate parity (RIRP) for fourteen Latin American countries. Utilizing the SPSM, we can classify the entire panel into a group of stationary series and a group of non-stationary series. We clearly identify how many and which series in the panel are stationary processes and provide robust evidence that clearly indicate RIRP holds true for ten countries. Our findings note that these countries' real interest rate convergence is a mean reversion toward RIRP equilibrium values in a non-linear way. Our results have important policy implications for these Latin American countries under study.
\end{abstract}

Keywords Real interest rate parity $\cdot$ Sequential panel selection method $\cdot$ Fourier transform JEL Classification $\mathrm{C} 23 \cdot \mathrm{F} 36$

Electronic supplementary material The online version of this article (doi:10.1007/s10258-014-0101-y) contains supplementary material, which is available to authorized users.

\footnotetext{
W. L. Zhang

Faculty of Finance and Banking, Shanxi University of Finance and Economics, Taiyuan, Shanxi, China

\section{H.-L. Chang}

Department of Accounting and Information, Ling Tung University, Taiwan, Republic of China

C.-W. Su

Department of Finance, Ocean University of China, 238, Songling Rd., Qingdao, Shandong, China e-mail: cwsu7137@gmail.com
} 